NBER WORKING PAPER SERIES

\title{
BEHAVIORAL ECONOMICS AND THE DEMAND FOR ALCOHOL: RESULTS FROM THE NLSY97
}

\author{
Henry Saffer \\ Dhaval Dave \\ Michael Grossman \\ Working Paper 18180 \\ http://www.nber.org/papers/w18180
}

\author{
NATIONAL BUREAU OF ECONOMIC RESEARCH \\ 1050 Massachusetts Avenue \\ Cambridge, MA 02138 \\ June 2012
}

The work on this project has been funded by grant 5R01AA020464 from the National Institute on Alcohol Abuse and Alcoholism, National Institute of Health, to the National Bureau of Economic Research. This grant is supported by the Common Fund, which is managed by the OD/Office of Strategic Coordination (OSC). The views expressed herein are those of the authors and do not necessarily reflect the views of the National Bureau of Economic Research.

NBER working papers are circulated for discussion and comment purposes. They have not been peerreviewed or been subject to the review by the NBER Board of Directors that accompanies official NBER publications.

(C) 2012 by Henry Saffer, Dhaval Dave, and Michael Grossman. All rights reserved. Short sections of text, not to exceed two paragraphs, may be quoted without explicit permission provided that full credit, including $(\mathcal{C}$ notice, is given to the source. 
Behavioral Economics and the Demand for Alcohol: Results from the NLSY97 Henry Saffer, Dhaval Dave, and Michael Grossman

NBER Working Paper No. 18180

June 2012

JEL No. D03,I18

\begin{abstract}
The behavioral economic model presented in this paper argues that the effect of advertising and price differ by past consumption levels. The model predicts that advertising is more effective in reducing consumption at high past consumption levels but less effective at low past consumption levels. Conversely, the model predicts that higher prices are effective in reducing consumption at low past consumption levels but less effective at high past consumption levels. Unlike the models used in most prior studies, this model predicts that the effects of policy on average consumption and on the upper end of the distribution are different.

Both FMM and Quantile models were estimated. The results from these regressions show that heavy drinkers are more responsive to advertising and less responsive to price than are moderate drinkers. The empirical evidence also supports the assumption that education is a proxy for self-regulation. The key conclusions are that restrictions on advertising are targeted at heavy drinkers and are an underutilized alcohol control policy. Higher excise taxes on alcohol reduce consumption by moderate drinkers and are of less importance in reducing heavy consumption.

Henry Saffer

NBER

365 Fifth Avenue, 5th Floor

New York, NY 10016-4309

hsaffer@gc.cuny.edu

Dhaval Dave

Bentley University

Department of Economics

175 Forest Street, AAC 195

Waltham, MA 02452-4705

and NBER

ddave@bentley.edu

Michael Grossman

Ph.D. Program in Economics

City University of New York Graduate Center

365 Fifth Avenue, 5th Floor

New York, NY 10016-4309

and NBER

mgrossman@gc.cuny.edu
\end{abstract}




\section{Introduction}

This paper presents a new empirical study of the effects of alcohol cues and price on alcohol consumption. The specific alcohol cues which are examined are those provided by alcohol advertising on TV and alcohol references included in TV programming. A novel feature of this study is that the empirical work is guided by a blend of behavioral economic and neoclassical economic theory. The resulting theoretical model benefits from the insights of behavioral economics while maintaining the empirical tractability of a conventional neoclassical demand model. Behavioral economic theory argues for a dual agent approach to examine the effects of advertising and price and neuroeconomic laboratory research provides evidence of a biological basis for this approach. The theoretical model employs the analytically convenient fiction of two separate underlying decision mechanisms but emphasizes a single decision outcome. The key conclusions of the theory is that heavy drinkers are more responsive to cues such as alcohol advertising and alcohol references in programming on TV and less responsive to price than are moderate drinkers. If this is the case, then restrictions on cues are targeted at heavy drinkers and are an important alcohol control policy. The theory also implies that, while price may limit the consumption of moderate drinkers, price is of limited importance in reducing heavy consumption. These assertions are tested with a large scale secondary data set.

In the U.S., alcohol advertising on TV is substantial. The advertising- to-sales ratio for alcohol is about 5 percent, while the typical industry advertising-to-sales ratio is about 2 to 3 percent. Data from Kantar Media show that alcohol advertising just on TV was about \$1.1 billion in 2009. There has not been much change in the overall level of expenditures on alcohol advertising on TV between 2002 and 2009. However, annual hours of alcohol advertising on national TV increased by about 50 percent and local TV hours declined by about 20 percent. Spirits advertising on TV has been a major growth area. According to Ad Age, 2011, for all media, spirits and blended liquors had an advertising-to-sales ratio of 14 . This large ratio comes 
mainly from the use of TV. Under the terms which ended prohibition, spirits producers voluntarily agreed to not use broadcast media for advertising. In 1996, the spirits industry abandoned this voluntary agreement and placed ads on cable TV stations. At that time, the four largest broadcasters $\mathrm{ABC}, \mathrm{CBS}$, Fox and NBC refused to run ads for spirits. However, gradually, local stations affiliated with NBC and CBS have been accepting spirits ads placed after 10 pm. Elliot (2009) reported that one alcohol ad shown in 15 major markets on CBS affiliates reached 31 percent of all American households.

Alcohol cues on TV also come from alcohol use and references in TV programming and are ubiquitous. Christensen, Henriksen and Roberts (2000) found that on prime-time TV, 71\% of all programming depicted alcohol use and $77 \%$ contained references to alcohol. Russell and Russell (2009) studied a sample of 144 unique episodes from eighteen shows based on Nielsen's top-rated prime-time television series on NBC, ABC, CBS, Fox, and WB including five situation comedies, one cartoon, and twelve dramas. They found that all the shows contained visual alcohol portrayals and verbal alcohol references.

Alcohol prices vary across the country although there has been little change in prices over time. Federal alcohol excise taxes have not changed since 1991. At the state level there have been a number of small changes since 2002 amounting to only a few cents per gallon. Data from the BLS shows that alcohol prices for at home consumption increased by about 33\% from 1999 to 2011 . Since the overall CPI increased by about $30 \%$ during this time period there has been little change in the real price of alcohol for at home consumption.

\section{Prior Studies}

There are a growing number of studies in the economics literature and in the public health literature on the effects of alcohol cues on alcohol consumption. However, few studies 
provide any information on potentially differential effects by consumption level. A review of economics studies by Gallet (2007) examined 132 studies of alcohol demand which included an advertising measure. Gallet reports a mean value for the advertising elasticity of 0.03 . He compares this to a value for the price elasticity of -0.535 and concludes that advertising has only a limited impact on alcohol consumption. However, the studies in the review do not distinguish the effects of advertising on heavy drinkers from the effects of advertising on moderate drinkers. Since most drinkers are in the moderate category, the failure to distinguish individuals by consumption level may mask the effect of advertising on heavy drinkers.

The public health literature provides a stronger consensus for a positive effect of alcohol cues than the economics literature. Again, few of these public health studies look for differences in the effect of advertising by consumption level. However, an experimental study by Koordeman et al. (2011) found that alcohol commercials prior to a movie led to increased consumption of alcohol, but only in heavy drinkers. Consistent with these results, McCusker (2001) found that memories of positive drinking outcomes are more accessible for heavy compared to moderate drinkers and Tapert et al. (2003) found that alcohol advertising leads to distinct patterns of brain activation, causing craving responses and affecting consumption decisions in heavy drinkers. Engels et al. (2009) tested experimentally whether portrayal of alcohol images in movies and commercials on television promotes actual drinking. They had young adult males watch a movie clip with two commercial breaks. The subjects were allowed to drink non-alcohol and alcoholic beverages. These participants were randomly assigned to one of four groups defined by increasing levels of exposure to alcohol portrayals. The participants assigned to the conditions with most alcohol portrayals in either movies or commercials consumed on average 1.5 glasses more than those in the condition with no alcohol portrayals. 
There are a number of studies in the economics literature on the effect of alcohol price on alcohol consumption. In contrast to studies on alcohol advertising, several studies of alcohol price look for differential effects by drinking level. Prior studies which examined heavy drinking find lower elasticities than those estimated for per capita drinking. A review by Wagenaar et al. (2009) reports a mean alcohol price elasticity of -0.51 for all drinking and a mean price elasticity of -0.28 for heavy drinking. Another review by Wagenaar, Tobler and Kromo (2010) of 50 studies examined the effects of alcohol price on various negative outcomes related to alcohol. They report price elasticities for alcohol related mortality of -0.50 , morbidity of -0.35 and lower elasticities for alcohol related violence, traffic crashes, sexually transmitted diseases and crime. These negative outcomes are probably more related to heavy drinking than to moderate drinking. These results suggest that the effects of price on heavy drinking, while smaller than the effects for moderate drinking, are not irrelevant.

Two prior studies of alcohol price effects are of particular interest since they provide guidance for the empirical strategy adopted in this paper. In estimating differential effects for heavy drinkers and other drinkers a key empirical concern is endogenous selection. Ayyagari et al. (2009) employ a finite mixture model (FMM) which bypasses selection on the dependent variable and requires only specification of the number of distinct population subgroups. Manning et al. (1995) employ a quantile approach which also bypasses selection on the dependent variable and simply requires definition of the quantiles. Interestingly, the results in both of these papers is consistent with the behavioral economic model presented in this paper. Also, both papers argue that the failure to differentiate policy effects by consumption level conceals important information.

Ayyagari et al. (2009) investigates the price elasticity of demand for alcohol using Health and Retirement Survey. They first estimate an overall price elasticity of -0.286 which is 
somewhat lower than Wagenaar, Salois and Komro (2009) reported mean. Next, they estimate a FMM with two components. The results for the first component show that a significant price elasticity of -1.6. The first component included both drinkers and non-drinkers and comprises $75 \%$ of the sample. The average number of drinks per day in component one is 0.129 . drinks per day. In the second component price is not significant with an estimated elasticity of -0.035 . This component comprises $25 \%$ of the sample and the average number of drinks per day in component two is 1.879 drinks per day. They conclude that there are two heterogeneous groups in the population. Most individual are either non-drinkers or moderate drinkers with an elastic demand for alcohol. However, a smaller group drinks more heavily and is unresponsive to price.

Manning et al. (1995) specifically examined the effect of the level of alcohol consumption on the price elasticity. They use the National Health Interview Survey with a weighted average of ACCRA beer, wine, and spirits prices and a two-part model which separates the dichotomous drinking participation decision from the choice of quantity consumed given participation. The price variable in the participation equation is significant while it is not in the consumption given participation equation. They estimate an overall participation elasticity of -0.55 . Next, they estimate a quantile regression using deciles of the consumption distribution. The results show that the moderate drinkers have the highest price elasticity which is -1.19 . The price elasticity declines as consumption increases from the median quantile. The price is insignificant in the quantile which includes the heaviest drinkers while all other quantiles are significant.

\section{Theory}

The theoretical model relies primarily on a theory of addiction and response to cues based on neurological evidence presented in a paper by Bernheim and Rangel (2004). This theory provides an advance in understanding how advertising affects alcohol consumption 
decisions and provides guidance for the specific functional form of this relationship. There are two key points in the theory. First, the theory argues that the role of advertising cues on alcohol consumption is a consequence of the forecast of a hedonic effect from alcohol, rather than the hedonic effect itself. Second, the theory argues that the forecast of a hedonic effect produced by advertising cues is proportional to past consumption rather than the advertising cues themselves.

The theoretical model employed in this paper assumes an analytically convenient fiction of two distinct neurological systems which act simultaneously to produce a single decision. These neurological systems have been given different labels such as system 1 and system 2 (Frederick and Kahneman, 2002) but will be referred to in this paper as the Hedonic system and the Rational system. The Hedonic system is a simple system for learning correlations between current conditions, decisions, and short-term rewards. It does not involve higher reasoning and is present in lower life forms as well as humans. The Hedonic system is efficient at learning simple action-reward correlations, but it is inflexible and unsophisticated in the sense that it can only learn about a limited range of near-term consequences. When decisions must be made very quickly, the Hedonic system dominates behavior. The main advantage of the Hedonic system is that it can produce rapid decisions with generally beneficial near-term outcomes provided that the environment is stable. It cannot, however, anticipate sufficiently delayed consequences, and when the environment changes, it cannot ignore irrelevant past experiences nor adjust forecasts prior to acquiring further experience. The Rational system develops causal models of the world and reasons out the implications of different choices. The Rational system needs time and cognitive resources to reason and make a choice. The Rational system addresses the shortcomings of the Hedonic system, but is comparatively slow. Self-regulation is a process which refers to the Rational system's ability to override the Hedonic system and is related to the more familiar concept of time preference. 
There is an important distinction between non-addictive consumption goods and addictive consumption goods in updating the Hedonic system. Individuals make consumption choices based to some degree on past consumption experiences. When an individual consumes a non-addictive good, there will be a post-consumption experience, which then updates the Hedonic system. That is, there is learning from the post-consumption experience and the predicted result of a future choice reflects this learning. However, an addictive substance interferes with the normal operation of the Hedonic system with a direct chemical effect on the process that leads the hedonic system to generate a choice. The consumption of the addictive good affects the Hedonic system both through the post-consumption effect and the direct chemical effect which distorts the learning process. The Hedonic system functions with systematically skewed information which leads to mistakes in decision making. An individual can try to compensate for this effect by exercising self-regulation, but cannot consciously correct it. Individuals appear to achieve different balances between these mechanisms which may result from differences in self-regulation and differences in the direct effect of alcohol on both systems. This may be, in part, why some individuals become heavy drinkers while others drink alcohol without excess.

External cues associated with consumption can produce a forecast of the hedonic effect which is separate from the actual hedonic effect. Alcohol advertising is one form of external cue. Bernheim and Rangel (2004) report on a series of neuroscience experiments on cues and the level of hedonic forecasts. Hedonic forecasting occurs as a result of activity in a certain part of the brain and is distinct from the hedonic experience itself. In these experiments, when subjects are presented with a cue followed by a reward, there is a corresponding level of neural activity. However, as experience with the reward continues, this neural activity occurs in response to the cue rather than the reward. When the reward is increased, but the cue remains 
constant, the neural activity increases in proportion to the new level of reward. That is, the hedonic forecast is proportional to past levels of consumption rather than proportional to the level of the cue. Thus, in the case of alcohol consumption, the same cue will produce a greater response in heavy drinkers than is produced in moderate drinkers.

The theoretical model underlying the empirical work relies on the neurological processes described above and on neoclassical economic theory. The model assumes that an individual makes a choice regarding the consumption of alcohol and a non-addictive substance. The consumption level chosen reflects a weighted average of consumption desired by the Hedonic system and consumption desired by the Rational system. The weights are a function of cues, past consumption and self-regulation. For clarity of exposition, consumption desired by the Hedonic system is a function of only past consumption and consumption desired by the Rational system is a function only of price. The theory can be represented by six relationships which are assumed to be linear without intercepts.

Equation (1) shows that actual consumption (C) is a weighted average of desired consumption by both systems. $\mathrm{W}_{\mathrm{h}}$ is the weight given to consumption desired by the Hedonic system $\left(C_{h}\right)$ and $\left(W_{r}\right)$ is consumption desired by the Rational system $\left(C_{r}\right)$.

(1) $C=W_{h} C_{h}+W_{r} C_{r}$

The second relationship shows that the weight given to consumption desired by the Hedonic system is a function of Cues, past consumption (PC) and self-regulation (SR). Cues can be provided by alcohol advertising and alcohol portrayals on TV.

(2) $W_{h}=\gamma_{1}$ Cues $+\gamma_{2} P C+\gamma_{3} S R$.

Since the two weights sum to one.

(3) $W_{r}=\left(1-W_{h}\right)=1-\gamma_{1}$ Cues $-\gamma_{2} P C-\gamma_{3} S R$. 
Consumption desired by the Hedonic system is determined by past consumption where $\alpha_{1}$ represents a heuristic process.

(4) $C_{h}=\alpha_{1} P C$.

The Rational system reflects the optimization of a standard constrained utility function.

Consumption desired by the Rational system is determined by price $(\mathrm{P})$.

(5) $C_{r}=\beta_{1} P$.

Substituting equations (2), (3), (4), and (5) into equation (1) results in the following estimable relationship:

(6) $C=\lambda_{1}{ }^{*} P+\lambda_{2} S^{*} P+\lambda_{3}$ Cues $^{\star} P+\lambda_{4} P C^{\star} P+\lambda_{5}$ Cues $^{*} P C+\lambda_{6} S R^{\star} P C$.

Equation (6) drops one squared term which would not be included in an empirical model due to potential problems with colinearity. Since the theory assumes that $\beta_{1}$ and $\gamma_{3}$ are negative, $\lambda_{1}, \lambda_{2}$, and $\lambda_{6}$ are negative while $\lambda_{3}, \lambda_{4}$ and $\lambda_{5}$ are positive.

The effect of price on consumption is shown by: $\partial \mathrm{C} / \partial \mathrm{P}=\lambda_{1}+\lambda_{2} \mathrm{SR}+\lambda_{3}$ Cues $+\lambda_{4} \mathrm{PC}$ $\lambda_{1}$ is negative but since $\lambda_{4}$ is positive, increases in past consumption offsets the negative effect of price on consumption. Since $\lambda_{3}$ is positive increases in Cues also offset the negative effect of price. Self-regulation increases the negative effect of price since $\lambda_{2}$ is negative. The effect of Cues on consumption is shown by: $\partial \mathrm{C} / \partial \mathrm{Cues}=\lambda_{3} P+\lambda_{5} P C+>0$. Since $\lambda_{3}$ and $\lambda_{5}$ are positive, the effect of Cues on consumption is positive. An increase in past consumption will increase the effect of Cues on consumption. The effect of self-regulation on consumption is shown by: $\partial \mathrm{C} / \partial \mathrm{SR}=\lambda_{2} \mathrm{P}+\lambda_{6} \mathrm{PC}<0$. Since $\lambda_{2}$ and $\lambda_{6}$ are negative, the effect of $\mathrm{SR}$ on consumption is negative. However, counter intuitively, the model predicts that higher levels of past consumption will increase the negative effect of self-regulation. 
3. Data

The working data set is based on data from the National Longitudinal Survey of Youth 1997 (NLSY97) from 2002 to 2009. NLSY97 is an annual longitudinal, nationally representative sample of 8984 individuals who were 12 to 16 years old as of December 31,1996 . The data are representative of the entire population including those not in school. Price and advertising data were merged to the NLSY97. The mean values and standard errors for all the variables are presented in table 1.

The alcohol consumption variable is based on two consumption measures provided in the NLSY97. The first measure is the number of days in the past thirty days that alcohol was consumed (drinking days per month). The second measure is the usual number of drinks consumed per day in the past thirty days (drinks per day). The empirical consumption variable is the product of these two variables and is drinks per month. A number of prior studies have used the same measure.

The independent variables from the NLSY97 measure economic, demographic, and other factors that may impact alcohol consumption. These variables include continuous measures of the respondent's income, education and age and age squared. Also included are dichotomous measures of the respondent's gender, race, Hispanic ethnicity, marital status school enrollment status and a variable for under age 21 . The NLSY97 has TV watching in years 2002 and 2007 which are reported as hours of TV watching per week. Data from Nielson indicate that overall TV viewing time during the 2002-2009 period was relatively stable. Thus a linear trend based on the 2002 and 2007 data for each individual was used to interpolate data for 2003-2006 and to extrapolate data for 2008 and 2009. Weekly hours of TV watching were multiplied by a value equal to the number of days in the month of interview divided by 7 . This converts TV watching to hours per month. 
Education is usually included in a demand for alcohol equation as a proxy for health knowledge but could be a proxy for self-regulation. Education could be a proxy for selfregulation since individuals who are better able to self-regulate have been shown to achieve higher levels of educational success (Mischel, Shoda and Peake, 1988). This does not imply that education has any casual effect on self-regulation. The ability to self-regulate is related to a number of individual factors including genetics and experience. The estimation results for education are compared to what would be expected if education proxied for self-regulation.

Both the probability of exposure to alcohol ads on TV and the probability of exposure to alcohol portrayals in programming increase with the hours of TV watching. To model this interaction the empirical proxy for alcohol cues on TV is an interaction term defined as the product of hours of TV watching and hours of alcohol advertising on TV per month. This variable (called All TV Cues) is a measure of the probability of exposure to alcohol cues on TV. Hours of TV watching is also tested as a measure of exposure to alcohol cues. The TV advertising data was purchased from Kantar Media and includes hours of alcohol ads on all local and national TV. Local TV includes data from the top 101 local markets and national TV includes Network TV, Syndicated TV and Cable network TV. Spanish Language TV was excluded since it has a limited audience. The top 101 local markets account for about 82 percent of the US population. National ads have no local variation but have monthly and yearly variation. Advertising is not defined as a stock since advertising is viewed in the behavioral economics framework as an external cue which can result in a shift toward the Hedonic system. The alcohol cue variable was appended to the NLSY97 by market, month and year.

The alcohol price data come from the American Chamber of Commerce Researchers Association (ACCRA). The data are the price of a six pack of Heineken less any deposit and are 
at the quarterly level for about 300 communities. These data were aggregated to the state level to reduce measurement error associated with a small number of observations in each community and adjusted for the $1983 \mathrm{CPI}$. These beer prices were appended to the NLSY97 by state and quarter.

\section{Estimation Issues and Results}

The goal of the empirical work is to estimate the effects of price, cues and self-regulation at different levels of past consumption. The inclusion of past consumption in the empirical equation would create bias since past consumption is correlated with current consumption and thus correlated with the equation error term. Stratifying the sample into two or more groups based on the individual's past consumption would also create bias due to endogenous selection which is again due to the correlation between current consumption and past consumption. However, the correlation between past and current consumption can be used to advantage with FMM and quantile regression. These methods allow for estimation of the effects of the independent variables at different levels of current consumption without stratification of the sample. Since higher levels of current consumption are associated with higher levels of past consumption, FMM and Quantile regressions may provide estimates of the effects of the independent variables at different levels of past consumption. The empirical models drop the interaction terms with price from equation (6) since, in log form, they are too collinear with the $\log$ of price.

To verify that current and lagged consumption are correlated in the NLSY97 data a regression of the natural log of lagged alcohol consumption on the natural log of current alcohol consumption, its square and a constant was estimated. This regression resulted in an intercept of 1.226 , a coefficient of 0.474 on current alcohol consumption and a coefficient of 0.0228 for

the squared term. All coefficients were significant at the 1 percent level and the R-squared was 
.35. This regression was used to predict values of past consumption using current consumption for nine deciles of current consumption. Predicted past consumption increases with each decile of actual past consumption and with each decile of current consumption. Thus, on average for each decile, higher values of current consumption are associated with higher values of past consumption making current consumption a good ordinal proxy for past consumption.

The first set of results presented are for the FMM estimation of equation (6). The FMM approach is useful as a test for two or more underlying distributions which represent heterogeneous subsamples or components in the overall sample. This approach requires only specification of the number of components and the probability distribution for each component. The estimated mean value of the dependent variable in each component provides a natural interpretation of what the component represents. The components may or may not represent significantly different alcohol consumption levels. However, Ayyagari et al. (2009) employed the FMM approach to estimate an alcohol demand function with two components and found that the two components differed significantly by consumption level and the components can thus be interpreted as moderate consumption and heavy consumption.

The FMM results presented in table 2 assume two components each with a normal distribution. Since natural log transformations of alcohol consumption, alcohol price and alcohol advertising are employed, the resulting coefficients represent elasticities. These elasticities are for consumption, conditional on positive consumption. Clustered standard errors at the individual level were employed. The results show that the probability that an individual is in component 1 is .69 and the mean value of alcohol consumption for component 1 is 8.08 drinks per month (2.09 in logs). The predicted past consumption for component 1 is 10.45 drinks per month. The results also show that the probability that an individual is in component 2 is . 31 and the average consumption in component 2 is 40 drinks per month (3.69 in logs). The predicted 
past consumption for component 2 is 27.23 drinks per month. Thus component 1 can be interpreted as consisting of individuals with moderate levels of current and past consumption and component 2 can be interpreted as consisting of individuals with high levels of current and past consumption. The coefficients estimated for component 1 can be interpreted as relevant to individuals with moderate levels of past consumption and the coefficients estimated for component 2 can be interpreted as relevant to individuals with high levels of past consumption.

The results show that moderate drinkers have a price elasticity of -.49 and that the price elasticity for heavy drinkers is insignificant. These results are consistent with the theoretical model which predicts that an increase in past consumption decreases the negative effect of price on current consumption. The results also show that in component 1 the alcohol cues elasticity is significant and equal to .05 . and in component 2 the alcohol cues elasticity is significant and equal to .10 . This is also consistent with the theoretical model which predicts that an increase in past consumption increases the positive effect of advertising on consumption. These results are also consistent with the review by Gallet (2007) who found an average alcohol price elasticity of -0.535 and alcohol advertising elasticity of .03 . The estimates reported by Gallet do not distinguish between heavy and moderate consumption and therefore primarily reflect moderate drinkers since moderate drinkers predominate in any random sample.

It was argued above that education may be a proxy for self-regulation. The theoretical model predicts that an increase in past consumption increases the negative effect of selfregulation on consumption. The results show that for drinkers with a low level of past consumption, both education and current enrollment in school are insignificant but both variables are negative and significant for drinkers with a high level of past consumption. The larger negative effect for drinkers with higher levels of past consumption is consistent with the interpretation of education as a proxy for self-regulation. 
The theoretical model has no predictions with respect to the effect of past consumption on the other included independent variables. The results show that age has a positive effect on moderate drinkers maximizing at age 25.8. However, age has no effect on heavy drinking. Being underage has a negative effect on moderate drinkers but no effect on heavy drinkers. Similarly, being Hispanic has a negative effect for moderate drinkers but no effect on heavy drinkers. Income has a positive effect for moderate drinkers but a negative effect for heavy drinkers. Marriage and being Black has a negative effect for both moderate and heavy drinkers. Finally, being male has a positive effect for both moderate and heavy drinkers.

The FMM approach also allows for estimation of the influence of each independent variable on the probability that an individual is in component 1 . These results show that the probability of being a moderate drinker is increased for those who are married, black or Hispanic but decreased for males. These results parallel the results from the two components. The remaining variables have no significant influence on the probability of being a moderate drinker rather than a heavy drinker.

Table 3 presents two alternative specifications of the alcohol demand function estimated with FMM. The model in panel A of table 3 includes all of the independent variables in table 2 and also includes state dummies. The results in panel A are essentially the same as those of table 2 with the exception that the price coefficients are no longer significant. The loss of significance for price is probably due to the limited time variation in the state level price data. Panel B of table 3 includes all of the independent variables in table 2 but employs the natural log of TV watching as the measure of exposure to alcohol cues on TV. The results in panel B are the same as those of table 2 with respect to sign and significance but differ in magnitude. 
The coefficient of TV watching for component 1 is larger than the TV Cues variable in table 3 and the difference between component 1 and 2 is not significant.

As noted in the introduction, Ayyagari et al. (2009) estimated price elasticities for a sample which included non-drinkers. However, they also estimated priced elasticities for a sample limited to drinkers. They used FMM with two components and their data are limited to individuals over age 50. In the full sample they found that the probability of being in component 1 was .60 and the probability of being in component 2 was .40. Mean consumption levels for the two components of the drinkers only sample were not provided although they state that component 1 is the larger group and can be assumed that it is also the moderate drinkers. In the sample limited to drinkers, the price elasticity in component 1 was -0.63 and the price elasticity in component 2 was not significant. These elasticity results are very similar to the results found with the younger NLSY97 sample used in this paper. Ayyagari et al. (2009) also present results for the two components, for education, using several alternative specifications and results for a variable defined as a longer financial planning horizon using one specification. A longer financial planning horizon is related to time preference and could also be a proxy for self-regulation. In all the results education and the longer financial planning horizon are positive in component 1 and negative in component 2. Education and the financial planning horizon increase the probability of drinking in component 1 which is due to the inclusion of non-drinkers. The negative effect for component 2 is consistent with the prediction that past consumption increases the negative effect of self-regulation. These results suggest that education and financial planning horizon are proxies for self-regulation. Similar results for education were found with the NLSY97.

The second approach used to estimate equation (6) is quantile regression. The quantile regression estimator uses all of the sample observations and thus does not require sample 
stratification. The quantile regression estimates the marginal effects of the independent variables at pre-specified quantiles of the dependent variable. These quantiles are simply percentiles. The quantile regression results are presented in tables 4 and 5 and employ the same specifications used in tables 2 and 3. Again, the natural log of alcohol consumption, alcohol price and alcohol cues on TV are employed and the coefficients represent elasticities for consumption given that consumption is positive. The quantile results for the $10^{\text {th }}$ to the 90 th quantiles are presented. Robust bootstrap standard errors are included based on 400 repetitions.

Table 4 includes alcohol price elasticities, alcohol cues elasticities and results for education. The price elasticities are all negative and four of these price elasticities are significant. The price elasticities show a general pattern of decline from the $10^{\text {th }}$ quantile to the $90^{\text {th }}$ quantile and are all insignificant after the $60^{\text {th }}$ quantile. That is, the price elasticity declines as current and past consumption increase which is predicted by the theoretical model. At the $30^{\text {th }}$ quantile the price elasticity is -0.506 which is the very close to the price elasticity estimated in component 1 with the FMM approach. The alcohol cues elasticities are all positive and significant. The cues elasticities show a general pattern of increase from the $10^{\text {th }}$ quantile to the $90^{\text {th }}$ quantile. That is, the alcohol cues elasticity increases as past consumption increases which is also predicted by the theoretical model. At the $30^{\text {th }}$ quantile the cues elasticity is .058 and at the $80^{\text {th }}$ quantile the cues elasticity is .105 . These are close to the values reported for component 1 and component 2 in the FMM results. The education coefficients are negative and significant which shows that education reduces consumption. The coefficients increase in absolute value from the $10^{\text {th }}$ quantile to the $90^{\text {th }}$ quantile which shows that the effect of education increases as past consumption increases. At the $30^{\text {th }}$ quantile an extra year of education reduces consumption by about $2 \%$ but at the $80^{\text {th }}$ quantile an extra year of education reduces consumption by about $7 \%$. Enrolled is insignificant from the $10^{\text {th }}$ to the $70^{\text {th }}$ quantile 
and then is negative and significant. This is the pattern expected for self-regulation which supports the hypothesis that education is a proxy for self-regulation and is similar to the FMM results.

The other variables in table 4 include age variables which are generally not significant but the underage variable is negative and significant in five of the nine quantiles. Income is positive and significant in the $10^{\text {th }}$ through the $70^{\text {th }}$ quantile and decreases as alcohol consumption increases. The demographic variables, Black, Hispanic and Married are all negative and significant in almost all quantiles. Male is positive and significant in all quantiles.

The quantile coefficients can be tested for significant differences between quantiles. These tests were done with the results from table 4 with a null hypothesis of no difference between the coefficients. The null hypothesis is rejected when the p values are .10 or less. This test was performed on the coefficients of price and TV Cues for all the permutations of quantile combinations. The results of these tests show that for price only the $10^{\text {th }}$ and $90^{\text {th }}$ quantiles are significantly different. However, for TV Cues, most quantiles which were two or more deciles apart were significantly different.

Table 5 presents two alternative specifications of the alcohol demand function estimated with quantile regressions. The model in panel $A$ of table 5 includes all of the independent variables in table 4 and also includes state dummies. The results in panel A are essentially the same as those of table 4 with the exception that the price coefficients are no longer significant which parallel the results in panel A of table 3. Panel B of table 5 includes all of the independent variables in table 4 but employs the natural log of TV watching as the measure of exposure to alcohol cues on TV. The results in panel B are the same as those of table 4 with respect to sign and significance but differ in magnitude. The coefficient of TV watching for the 10 quantile 
is significantly different than the coefficient for the $80^{\text {th }}$ and $90^{\text {th }}$ quantile. These results support the theoretical model.

As noted in the introduction, Manning et al. (1995) estimated alcohol price elasticities with quantile regressions. They found the highest price elasticity was at the $50^{\text {th }}$ quantile which declined moving to both extremes. They reported a conditional price elasticity at the $50^{\text {th }}$ quantile of -0.64 and approximately zero at the $90^{\text {th }}$ quantile. The hypothesis of equality of these two coefficients is rejected. Using the NLSY97 data the conditional price elasticity at the $50^{\text {th }}$ quantile is -0.72 , at the $60^{\text {th }}$ quantile is -.53 and approximately zero at higher quantiles. Manning et al. also report the effect of four or more years of college on alcohol consumption. It is negative and significant at the $5^{\text {th }}$ and $95^{\text {th }}$ quantile and increases in absolute value as alcohol consumption increases. These results are consistent with the assertion that education is a proxy for self-regulation and similar to results for education which were found with the NLSY97.

\section{Conclusions}

The distribution of alcohol consumption indicates that most individuals who drink are moderate drinkers and only a minority of individuals are heavy drinkers. An efficient alcohol control policy would target these heavy drinkers since this group is responsible for much of the social costs of alcohol. Moderate alcohol consumption probably causes no harm and might be beneficial to health. The reduction of alcohol cues in the form of TV advertising and TV placements and the increase in alcohol price through higher excise taxes are important alcohol control options and are the primary focus of this paper. All of the prior studies of alcohol advertising focus on average consumption and most of the prior studies of taxes and price focus on average consumption. The focus on average consumption is based on the implicit assumption that lower average consumption implies lower consumption at the upper end of the distribution. 
The behavioral economic model presented in this paper argues that the effect of advertising and price differ by past consumption levels. The model predicts that advertising is more effective in reducing consumption at high past consumption levels but less effective at low past consumption levels. Conversely, the model predicts that higher prices are effective in reducing consumption at low past consumption levels but less effective at high past consumption levels. Past consumption levels and current consumption levels are highly correlated and thus current consumption is a good ordinal proxy for past consumption. Unlike the models used in most prior studies, this model predicts that the effects of policy on average consumption and on the upper end of the distribution are different.

Both FMM and Quantile models were estimated. The results from these regressions show that heavy drinkers are more responsive to advertising and less responsive to price than are moderate drinkers. The empirical evidence also supports the assumption that education is a proxy for self-regulation. The key conclusions are that restrictions on advertising are targeted at heavy drinkers and are an underutilized alcohol control policy. Higher excise taxes on alcohol reduce consumption by moderate drinkers and are of less importance in reducing heavy consumption.

The empirical results are not proof of the behavioral model since the estimated specifications could have been generated by alternative theoretical models. However, there is also laboratory evidence supporting the behavioral model. If the behavioral model is an accurate representation of behavior there is an additional implication about the effect of cues on alcohol consumption. In the neoclassical approach, advertising is information which can change perceptions of the product and act as a complement to consumption. In this view, the various streams of information about alcohol are rationally weighed and according to revealed 
preference the individual's observed consumption is optimal. In the behavioral economic model, advertising is a cue which increases the probability that alcohol consumption is heuristically determined. In the behavioral model the effects of advertising are not easily dismissed by heavy drinkers. The conclusion from the behavioral economic model is that advertising induced consumption is not optimal for all individuals and may be a particular concern for those drinkers most at risk from alcohol. 


\section{References}

Ayyagari, P., Deb, P., Fletcher, F., Gallo, W., Sindelar J., "Sin Taxes: Do Heterogeneous Responses Undercut Their Value?”, NBER Working Paper No. 15124 July 2009.

Bernheim B. and Rangel, A., "Addiction and Cue-Triggered Decision Processes", American Economic Review, Volume, 94 iss. 5 Pg. 1558-1590, 2004,

Bureau of Labor Statistics, http://www.bls.gov/news.release/cpi.t01.htm

Christensen, P., Henriksen, L., Roberts, D., Substance Use in Popular Prime-Time Television, Washington, DC: Office of National Drug Control Policy, 2000.

Elliot, S., More Liquor Ads Pour Onto Broadcast TV, New York Times, February 9, 2009.

Engels, R., Hermans, R., van Baaren, R., Hollenstein, T., and Sander, M., "Alcohol Portrayal on Television Affects Actual Drinking Behaviour", Alcohol and Alcoholism , vol.44, iss.3, pg. 244, 2009.

Gallet, C. The demand for alcohol: a meta-analysis of elasticities, Australian Journal Of Agricultural \& Resource Economics, 51(2):121-135, June 2007.

Kantar Media, http://www.kantarmedia.com/.

Kahneman D. and Frederick S., "Representativeness revisited: Attribute substitution in intuitive judgment" in Heuristics of Intuitive Judgment: Extensions and Applications, Gilovich, T., Griffin D., and Kahneman D., eds. New York: Cambridge University Press, 2002.

Koordeman, R., Anschutz, D., and Engels, R. "Exposure to Alcohol Commercials in Movie Theaters Affects Actual Alcohol Consumption in Young Adult High Weekly Drinkers: An Experimental Study", The American Journal on Addictions, 20: 285-291, 2011.

Manning, W., Bloomberg, L., and Mouton, I., "The Demand for Alcohol: Differential Response to Price", Journal of Health Economics, vol. 14, 1995.

McCusker, C., "Cognitive biases and addiction: an evolution in theory and method", Addiction, 96(1):47-56, January 2001.

Mischel W., Shoda Y., Peake P., "The nature of adolescent competencies predicted by preschool delay of gratification”, Journal Of Personality And Social Psychology, 54(4):687-696, April 1988.

Russell C., Russell, D., "Alcohol Messages in Prime-Time Television Series”, Journal of Consumer Affairs, 43(1): pp.108-128, 2009.

Tapert, S., Cheung,E., Brown, G., Frank, L., Paulus, M., Schweinsburg, A., Meloy, M., Brown, S., "Neural Response to Alcohol Stimuli in Adolescents With Alcohol Use Disorder", Archives of General Psychiatry, 60:727-735, 2003. 
Wagenaar, A., Salois, C., Matthew J., Komro, M. and Kelli A., "Effects of Beverage Alcohol Price and Tax Levels on Drinking: A Meta-analysis of 1003 Estimates from 112 Studies", Addiction, vol. 104, no. 2, pp. 179-190(12), February 2009.

Wagenaar, A., Tobler, A.L., and Kromo K.A., "Effects of Alcohol Tax and Price Policies on Morbidity and Mortality: A Systematic Review, American Journal of Public Health, Vol. 100, No. 11, pp. 2270-2278, November 2010. 
Table 1

Table of Weighted Means

NLSY97

\begin{tabular}{|c|c|c|}
\hline variable name & definition & mean \\
\hline LN CONSUMPTION & Natural log of drinks per month. & 2.683 \\
\hline LN PRICE & $\begin{array}{l}\text { Natural log of state average ACCRA } \\
\text { beer price for a six-pack of Heineken } \\
\text { adjusted for CPI based on } 1983 \\
\text { prices. }\end{array}$ & 1.194 \\
\hline AGE & Age in years. & 23.782 \\
\hline AGE SQUARED & Square of Age in years. & 572.404 \\
\hline UNDERAGE & $\begin{array}{l}\text { Dichotomous variable equal to one } \\
\text { for individuals under age } 21 \text {. }\end{array}$ & 0.114 \\
\hline REAL INCOME & $\begin{array}{l}\text { Income adjusted for CPI based on } \\
1983 \text { prices. }\end{array}$ & $\$ 9,675.321$ \\
\hline EDUCATION & Years of education completed. & 13.601 \\
\hline MARRIED & $\begin{array}{l}\text { Dichotomous variable equal to one } \\
\text { for individuals who are married. }\end{array}$ & 0.195 \\
\hline MALE & $\begin{array}{l}\text { dichotomous variable equal to one } \\
\text { for individuals who are male. }\end{array}$ & 0.533 \\
\hline BLACK & $\begin{array}{l}\text { dichotomous variable equal to one } \\
\text { for individuals who are Black. }\end{array}$ & 0.112 \\
\hline HISPANIC & $\begin{array}{l}\text { Dichotomous variable equal to one } \\
\text { for individuals who are Hispanic. }\end{array}$ & 0.121 \\
\hline LN (ALL TV Cues) & $\begin{array}{l}\text { Natural log of TV alcohol advertising } \\
\text { times TV watching in hours per } \\
\text { month. }\end{array}$ & 8.011 \\
\hline LN (TV) & $\begin{array}{l}\text { Natural log of TV watching in hours } \\
\text { per month. }\end{array}$ & 2.341 \\
\hline IN SCHOOL & $\begin{array}{l}\text { Dichotomous variable equal to one } \\
\text { for individuals enrolled in school. }\end{array}$ & 0.272 \\
\hline 2002 & time dummy & 0.109 \\
\hline 2003 & time dummy & 0.105 \\
\hline 2004 & time dummy & 0.110 \\
\hline 2005 & time dummy & 0.121 \\
\hline 2006 & time dummy & 0.125 \\
\hline 2007 & time dummy & 0.139 \\
\hline 2008 & time dummy & 0.141 \\
\hline Observations & & 24,443 \\
\hline
\end{tabular}


Table 2

FMM Results Ln(Alcohol Consumption)

\begin{tabular}{|c|c|c|c|}
\hline & $(1)$ & $(2)$ & (3) \\
\hline VARIABLES & component1 & component2 & $\begin{array}{l}\text { Probability of } \\
\text { component } 1\end{array}$ \\
\hline \multirow[t]{2}{*}{ In (PRICE) } & $-0.488^{*}$ & -0.0982 & 0.0149 \\
\hline & $(0.282)$ & $(0.363)$ & $(0.0354)$ \\
\hline \multirow[t]{2}{*}{ In (ALL TV CUES) } & $0.0527^{\star \star \star}$ & $0.0999^{* \star \star}$ & -0.00206 \\
\hline & $(0.0158)$ & $(0.0200)$ & $(0.00182)$ \\
\hline \multirow[t]{2}{*}{ AGE } & $0.191^{*}$ & 0.0138 & 0.00396 \\
\hline & $(0.109)$ & $(0.143)$ & $(0.0174)$ \\
\hline \multirow[t]{2}{*}{ AGE SQUARED } & $-0.00377^{\star}$ & -0.000528 & $-8.31 e-05$ \\
\hline & $(0.00221)$ & $(0.00293)$ & $(0.000352)$ \\
\hline \multirow[t]{2}{*}{ UNDERAGE } & $-0.129^{\star \star}$ & -0.0581 & 0.00645 \\
\hline & $(0.0570)$ & $(0.0726)$ & $(0.00993)$ \\
\hline \multirow[t]{2}{*}{ REAL INCOME } & $1.32 \mathrm{e}-05^{\star \star \star}$ & $-1.16 \mathrm{e}-05^{\star \star \star}$ & $-3.53 e-07$ \\
\hline & $(1.98 e-06)$ & $(4.23 e-06)$ & $(2.24 \mathrm{e}-07)$ \\
\hline \multirow[t]{2}{*}{ EDUCATION } & -0.0103 & $-0.112^{* * t}$ & -0.000288 \\
\hline & $(0.00889)$ & $(0.0127)$ & $(0.000811)$ \\
\hline \multirow[t]{2}{*}{ MARRIED } & $-0.532^{\star \star \star}$ & $-0.308^{\star \star \star}$ & $0.0180^{\star \star \star}$ \\
\hline & $(0.0376)$ & $(0.0896)$ & $(0.00468)$ \\
\hline \multirow[t]{2}{*}{ MALE } & $0.535^{\star * \star}$ & $0.656^{\star \star *}$ & $-0.0245^{\star * *}$ \\
\hline & $(0.0405)$ & $(0.0530)$ & $(0.00354)$ \\
\hline \multirow[t]{2}{*}{ BLACK } & $-0.517^{\star \star \star}$ & $-0.273^{\star \star \star}$ & $0.0240^{\star * *}$ \\
\hline & $(0.0409)$ & $(0.0990)$ & $(0.00457)$ \\
\hline \multirow[t]{2}{*}{ HISPANIC } & $-0.222^{* \star \star}$ & 0.0490 & $0.00841^{*}$ \\
\hline & $(0.0421)$ & $(0.0643)$ & $(0.00448)$ \\
\hline \multirow[t]{2}{*}{ IN SCHOOL } & -0.00532 & $-0.120^{\star *}$ & -0.00510 \\
\hline & $(0.0311)$ & $(0.0498)$ & $(0.00443)$ \\
\hline \multirow[t]{2}{*}{2002} & 0.145 & 0.105 & 0.000292 \\
\hline & $(0.0885)$ & $(0.121)$ & $(0.0107)$ \\
\hline \multirow[t]{2}{*}{2003} & $0.171^{* *}$ & 0.0572 & 0.00189 \\
\hline & $(0.0779)$ & $(0.107)$ & $(0.00983)$ \\
\hline \multirow[t]{2}{*}{2004} & 0.0653 & -0.00659 & -0.00176 \\
\hline & $(0.0702)$ & $(0.0967)$ & $(0.00914)$ \\
\hline \multirow[t]{2}{*}{2005} & 0.0945 & -0.0469 & -0.000313 \\
\hline & $(0.0606)$ & $(0.0872)$ & $(0.00857)$ \\
\hline \multirow[t]{2}{*}{2006} & 0.0315 & -0.00770 & 0.00451 \\
\hline & $(0.0519)$ & $(0.0743)$ & $(0.00791)$ \\
\hline \multirow[t]{2}{*}{2007} & 0.0449 & -0.107 & 0.000713 \\
\hline & $(0.0450)$ & $(0.0652)$ & $(0.00726)$ \\
\hline \multirow[t]{2}{*}{2008} & 0.0437 & -0.0754 & -0.000696 \\
\hline & $(0.0395)$ & $(0.0563)$ & $(0.00692)$ \\
\hline \multirow[t]{2}{*}{ Constant } & 0.897 & $4.576^{\star *}$ & $0.617^{* *}$ \\
\hline & $(1.649)$ & $(2.110)$ & $(0.243)$ \\
\hline Observations & 24443 & 24443 & 24443 \\
\hline Probability & .6867 & .3133 & \\
\hline & enthesis * & $01,{ }^{\star *} \mathrm{p}<$ & $p<0.1$ \\
\hline
\end{tabular}




\begin{tabular}{|l|l|l|}
\hline \multicolumn{3}{|c|}{ Table 3 } \\
\hline \multicolumn{3}{|c|}{ STATE DUMMIES* } \\
FMM panel A Ln(Alcohol Consumption) \\
\hline & $(1)$ & $(2)$ \\
\hline VARIABLES & component1 & component2 \\
\hline In Price & -0.129 & -0.308 \\
\hline & $(0.363)$ & $(0.530)$ \\
\hline EDUCATION & -0.0104 & $-0.113^{\star * \star}$ \\
\hline & $(0.00908)$ & $(0.0133)$ \\
\hline LN(ALL TV CUES) & $0.0499^{* * *}$ & $0.0947^{\star * *}$ \\
\hline & $(0.0154)$ & $(0.0201)$ \\
\hline IN SCHOOL & -0.0187 & $-0.116^{* *}$ \\
\hline & $(0.0306)$ & $(0.0482)$ \\
\hline State and Time Dummies & Yes & Yes \\
\hline Constant & 0.0315 & $5.424^{* *}$ \\
\hline & $(1.813)$ & $(2.482)$ \\
\hline Observations & 24443 & 24443 \\
\hline Probability & .6940 & .3060 \\
\hline \multicolumn{2}{|c|}{} \\
\hline
\end{tabular}

\begin{tabular}{|c|c|c|}
\hline \multicolumn{3}{|c|}{$\begin{array}{c}\text { Alternative TV Variable* } \\
\text { FMM panel B Ln(Alcohol Consumption) }\end{array}$} \\
\hline & (1) & (2) \\
\hline VARIABLES & component1 & component2 \\
\hline \multirow[t]{2}{*}{ In Price } & $-0.466^{*}$ & -0.091 \\
\hline & $(0.281)$ & $(0.366)$ \\
\hline \multirow[t]{2}{*}{ EDUCATION } & -0.00937 & $-0.113^{\star \star \star}$ \\
\hline & $(0.00897)$ & $(0.0130)$ \\
\hline \multirow[t]{2}{*}{ LN(TV ) } & $0.0784^{\star * \star}$ & $0.1004^{* \star *}$ \\
\hline & $(0.0181)$ & $(0.0239)$ \\
\hline \multirow{2}{*}{ IN SCHOOL } & -0.000657 & $-0.121^{\star \star}$ \\
\hline & $(0.0310)$ & $(0.0509)$ \\
\hline Time Dummies & Yes & Yes \\
\hline \multirow{2}{*}{ Constant } & 1.000 & $4.932^{* *}$ \\
\hline & $(1.643)$ & (2.133) \\
\hline Observations & 24443 & 24443 \\
\hline Probability & .6915 & .3084 \\
\hline \multicolumn{3}{|c|}{$\begin{array}{l}\text { Robust standard errors in parentheses. }{ }^{* *} p<0.01,{ }^{* *} \\
p<0.05,{ }^{*} p<0.1{ }^{*} \text { The full set of independent variables fron } \\
\text { table } 2 \text { were included but only the key results are reported } \\
\text { in this table to economize on space. }\end{array}$} \\
\hline
\end{tabular}


Table 4

Quantile Regressions Ln(Alcohol Consumption)

\begin{tabular}{|c|c|c|c|c|c|c|c|c|c|}
\hline & (1) & (2) & (3) & (4) & (5) & (6) & (7) & (8) & (9) \\
\hline Variables & q10 & q20 & q30 & q40 & q50 & q60 & $q 70$ & $q 80$ & q90 \\
\hline \multirow[t]{2}{*}{ In (PRICE) } & $-0.982^{\star \star \star}$ & -0.392 & $-0.506^{\star *}$ & $-0.389^{*}$ & $-0.381^{*}$ & $-0.483^{* *}$ & -0.336 & -0.224 & -0.0785 \\
\hline & $(0.339)$ & $(0.296)$ & $(0.226)$ & $(0.213)$ & $(0.213)$ & $(0.219)$ & $(0.215)$ & $(0.193)$ & $(0.294)$ \\
\hline \multirow[t]{2}{*}{$\begin{array}{l}\text { In (ALL TV } \\
\text { CUES) }\end{array}$} & $0.0422^{\star *}$ & $0.0499^{* * *}$ & $0.0584^{* \star \star}$ & $0.0649^{* \star *}$ & $0.0763^{\star \star \star}$ & $0.0833^{\star \star \star}$ & $0.0919^{* \star *}$ & $0.105^{\star \star \star}$ & $0.0926^{\star \star \star}$ \\
\hline & $(0.0182)$ & $(0.0142)$ & $(0.0132)$ & $(0.0137)$ & $(0.0119)$ & $(0.0123)$ & $(0.0113)$ & $(0.0112)$ & $(0.0144)$ \\
\hline \multirow[t]{2}{*}{ EDUCATION } & -0.00748 & $-0.0195^{\star \star \star}$ & $-0.0191^{\star \star \star}$ & $-0.0274^{\star \star \star}$ & $-0.0369^{\star \star \star}$ & $-0.0435^{\star \star \star}$ & $-0.0551^{\star * \star}$ & $-0.0648^{\star * \star}$ & $-0.0892^{\star \star \star}$ \\
\hline & $(0.00780)$ & $(0.00648)$ & $(0.00555)$ & $(0.00523)$ & $(0.00478)$ & $(0.00488)$ & $(0.00495)$ & $(0.00443)$ & $(0.00627)$ \\
\hline \multirow[t]{2}{*}{ IN SCHOOL } & -0.0306 & -0.0213 & -0.0140 & 0.000333 & -0.0152 & -0.0242 & $-0.0412^{*}$ & $-0.0760^{* * *}$ & $-0.0913^{* * *}$ \\
\hline & $(0.0367)$ & $(0.0307)$ & $(0.0295)$ & $(0.0267)$ & $(0.0279)$ & $(0.0256)$ & $(0.0248)$ & $(0.0232)$ & $(0.0324)$ \\
\hline \multirow[t]{2}{*}{ AGE } & $0.260^{*}$ & $0.269^{\star *}$ & 0.193 & 0.0754 & 0.0709 & 0.0898 & 0.102 & 0.0831 & -0.162 \\
\hline & $(0.145)$ & $(0.126)$ & $(0.119)$ & $(0.113)$ & $(0.106)$ & $(0.107)$ & $(0.113)$ & $(0.112)$ & $(0.113)$ \\
\hline \multirow[t]{2}{*}{ AGE SQUARED } & $-0.00484^{*}$ & $-0.00548^{\star *}$ & -0.00390 & -0.00152 & -0.00147 & -0.00192 & -0.00198 & -0.00173 & 0.00305 \\
\hline & $(0.00291)$ & $(0.00255)$ & $(0.00243)$ & $(0.00231)$ & $(0.00215)$ & $(0.00216)$ & $(0.00230)$ & $(0.00227)$ & $(0.00233)$ \\
\hline \multirow[t]{2}{*}{ UNDERAGE } & -0.00426 & -0.116 & $-0.154^{* \star}$ & $-0.241^{* \star \star}$ & $-0.207^{* * \star}$ & $-0.151^{* *}$ & -0.0860 & -0.0244 & $-0.144^{* \star}$ \\
\hline & $(0.0893)$ & $(0.0796)$ & $(0.0680)$ & $(0.0665)$ & $(0.0642)$ & $(0.0693)$ & $(0.0644)$ & $(0.0643)$ & $(0.0698)$ \\
\hline \multirow[t]{2}{*}{ REAL INCOME } & $1.52 \mathrm{e}-05^{\star \star \star}$ & $1.05 \mathrm{e}-05^{\star \star \star}$ & $9.35 \mathrm{e}-06^{\star \star \star}$ & $8.65 \mathrm{e}-06^{\star \star \star}$ & $6.34 \mathrm{e}-06^{\star \star \star}$ & $5.12 \mathrm{e}-06^{\star \star \star}$ & $2.90 \mathrm{e}-06^{\star \star}$ & $3.78 \mathrm{e}-07$ & $-1.97 e-06$ \\
\hline & $(1.86 \mathrm{e}-06)$ & $(1.50 \mathrm{e}-06)$ & $(1.41 \mathrm{e}-06)$ & $(1.39 \mathrm{e}-06)$ & $(1.32 \mathrm{e}-06)$ & $(1.36 \mathrm{e}-06)$ & $(1.32 \mathrm{e}-06)$ & $(1.15 e-06)$ & $(1.52 \mathrm{e}-06)$ \\
\hline \multirow[t]{2}{*}{ MARRIED } & $-0.501^{* * *}$ & $-0.573^{* \star *}$ & $-0.554^{* * *}$ & $-0.603^{* * *}$ & $-0.556^{* * *}$ & $-0.537^{* * *}$ & $-0.518^{* * *}$ & $-0.474^{* * *}$ & $-0.409^{* * *}$ \\
\hline & $(0.0464)$ & $(0.0386)$ & $(0.0303)$ & $(0.0295)$ & $(0.0319)$ & $(0.0285)$ & $(0.0297)$ & $(0.0269)$ & $(0.0360)$ \\
\hline \multirow[t]{2}{*}{ MALE } & $0.468^{\star \star \star}$ & $0.607^{\star \star \star}$ & $0.669^{\star \star \star}$ & $0.650^{\star \star \star}$ & $0.680^{\star \star \star}$ & $0.694^{\star \star \star}$ & $0.674^{\star * *}$ & $0.644^{* * *}$ & $0.649^{\star \star \star}$ \\
\hline & $(0.0399)$ & $(0.0306)$ & $(0.0274)$ & $(0.0225)$ & $(0.0235)$ & $(0.0223)$ & $(0.0206)$ & $(0.0205)$ & $(0.0275)$ \\
\hline \multirow[t]{2}{*}{ BLACK } & $-0.461^{* \star *}$ & $-0.541^{* \star *}$ & $-0.538^{\star \star \star}$ & $-0.591^{\star * \star}$ & $-0.577^{* \star \star}$ & $-0.587^{\star \star \star}$ & $-0.552^{\star \star \star}$ & $-0.498^{\star \star \star}$ & $-0.390^{\star \star \star}$ \\
\hline & $(0.0545)$ & $(0.0431)$ & $(0.0285)$ & $(0.0304)$ & $(0.0318)$ & $(0.0298)$ & $(0.0270)$ & $(0.0313)$ & $(0.0446)$ \\
\hline \multirow[t]{2}{*}{ HISPANIC } & $-0.185^{\star * *}$ & $-0.202^{* * *}$ & $-0.209^{* * *}$ & $-0.217^{* \star *}$ & $-0.219^{\star \star *}$ & $-0.187^{\star \star *}$ & $-0.141^{\star \star *}$ & $-0.0849^{* * *}$ & -0.0120 \\
\hline & $(0.0452)$ & $(0.0370)$ & $(0.0349)$ & $(0.0305)$ & $(0.0264)$ & $(0.0322)$ & $(0.0307)$ & $(0.0310)$ & $(0.0346)$ \\
\hline \multirow[t]{2}{*}{ Constant } & 0.166 & -0.798 & 0.855 & 2.389 & $2.820^{*}$ & $3.339^{\star *}$ & $3.010^{*}$ & $3.374^{\star *}$ & $6.959^{\star \star \star}$ \\
\hline & $(2.158)$ & $(1.742)$ & $(1.616)$ & $(1.517)$ & $(1.512)$ & $(1.627)$ & $(1.616)$ & $(1.504)$ & $(1.687)$ \\
\hline Observations & 24,443 & 24,443 & 24,443 & 24,443 & 24,443 & 24,443 & 24,443 & 24,443 & 24,443 \\
\hline $\begin{array}{l}\text { Predicted past } \\
\text { drinks per } \\
\text { month }\end{array}$ & 4.79 & 6.86 & 8.58 & 11.46 & 14.56 & 17.32 & 22.26 & 28.8 & 42.22 \\
\hline
\end{tabular}


Table 5 STATE DUMMIES *Quantile Panel A Ln(Alcohol Consumption)

\begin{tabular}{|c|c|c|c|c|c|c|c|c|c|}
\hline & (1) & (2) & (3) & (4) & (5) & (6) & (7) & (8) & (9) \\
\hline VARIABLES & $q 10$ & q20 & q30 & $q 40$ & q50 & 960 & $q 70$ & q80 & q90 \\
\hline \multirow[t]{2}{*}{ In Price } & -0.233 & 0.191 & -0.192 & 0.172 & -0.00121 & -0.363 & -0.303 & -0.116 & -0.0645 \\
\hline & $(0.556)$ & $(0.457)$ & $(0.416)$ & $(0.393)$ & $(0.383)$ & $(0.391)$ & $(0.362)$ & $(0.384)$ & $(0.428)$ \\
\hline \multirow[t]{2}{*}{ EDUCATION } & -0.00514 & $-0.0172^{\star \star \star}$ & $-0.0190^{\star \star \star}$ & $-0.0263^{\star \star \star}$ & $-0.0348^{\star \star \star}$ & $-0.0436^{\star \star \star}$ & $-0.0561^{* \star \star}$ & $-0.0688^{\star \star \star}$ & $-0.0906^{\star \star \star}$ \\
\hline & $(0.0459)$ & $(0.0362)$ & $(0.0357)$ & $(0.0305)$ & $(0.0282)$ & $(0.0324)$ & $(0.0312)$ & $(0.0325)$ & $(0.0360)$ \\
\hline \multirow[t]{2}{*}{$\begin{array}{l}\text { Ln (ALL TV } \\
\text { CUES) }\end{array}$} & $0.0410^{\star *}$ & $0.0464^{\star \star \star}$ & $0.0538^{* * *}$ & $0.0661^{* * *}$ & $0.0723^{\star * \star}$ & $0.0853^{\star * \star}$ & $0.0892^{* * *}$ & $0.105^{\star \star *}$ & $0.0873^{\star \star \star}$ \\
\hline & $(0.0179)$ & $(0.0146)$ & $(0.0134)$ & $(0.0125)$ & $(0.0122)$ & $(0.0123)$ & $(0.0122)$ & $(0.0123)$ & $(0.0157)$ \\
\hline \multirow[t]{2}{*}{ ENROLLED } & -0.0259 & -0.0217 & -0.0193 & -0.0159 & -0.0210 & -0.0285 & $-0.0462^{*}$ & $-0.0695^{\star * *}$ & $-0.0894^{* * *}$ \\
\hline & $(0.0406)$ & $(0.0313)$ & $(0.0296)$ & $(0.0265)$ & $(0.0262)$ & $(0.0258)$ & $(0.0263)$ & $(0.0268)$ & $(0.0320)$ \\
\hline \multirow[t]{2}{*}{ CONSTANT } & -3.006 & -2.943 & 0.426 & 0.899 & 1.827 & 2.891 & $2.959^{*}$ & $3.550^{*}$ & $6.704^{\star \star \star}$ \\
\hline & $(2.712)$ & $(2.272)$ & (2.093) & $(1.901)$ & $(1.817)$ & $(1.842)$ & $(1.767)$ & $(1.850)$ & $(2.027)$ \\
\hline $\begin{array}{l}\text { State and Time } \\
\text { Dummies }\end{array}$ & Yes & Yes & Yes & Yes & Yes & Yes & Yes & Yes & Yes \\
\hline Observations & 24,443 & 24,443 & 24,443 & 24,443 & 24,443 & 24,443 & 24,443 & 24,443 & 24,443 \\
\hline
\end{tabular}

Alternative TV Variable Quantile Panel B Ln(Alcohol Consumption)

\begin{tabular}{|c|c|c|c|c|c|c|c|c|c|}
\hline & (1) & (2) & (3) & (4) & (5) & (6) & (7) & (8) & (9) \\
\hline VARIABLES & q10 & q20 & q30 & q40 & q50 & 960 & q70 & 980 & q90 \\
\hline \multirow[t]{2}{*}{ In Price } & $-0.949^{* \star *}$ & -0.313 & $-0.492^{* \star}$ & -0.305 & $-0.419^{*}$ & $-0.435^{*}$ & $-0.406^{*}$ & -0.257 & 0.167 \\
\hline & $(0.335)$ & $(0.303)$ & $(0.227)$ & $(0.220)$ & $(0.215)$ & $(0.223)$ & $(0.219)$ & $(0.212)$ & $(0.266)$ \\
\hline \multirow[t]{2}{*}{ EDUCATION } & -0.00702 & $-0.0211^{\star \star \star}$ & $-0.0179^{\star \star \star}$ & $-0.0267^{* * *}$ & $-0.0360^{\star \star \star}$ & $-0.0412^{\star \star \star}$ & $-0.0520^{* * *}$ & $-0.0661^{\star \star \star}$ & $-0.0909^{\star \star \star}$ \\
\hline & $(0.00816)$ & $(0.00699)$ & $(0.00582)$ & $(0.00575)$ & $(0.00512)$ & $(0.00482)$ & $(0.00465)$ & $(0.00482)$ & $(0.00619)$ \\
\hline \multirow[t]{2}{*}{ Ln (TV CUES) } & $0.0700^{\star * \star}$ & $0.0741^{* * *}$ & $0.0792^{\star \star \star}$ & $0.0915^{\star \star \star}$ & $0.104^{* * *}$ & $0.109^{* * *}$ & $0.108^{\star \star \star}$ & $0.116^{* * *}$ & $0.0981^{* * *}$ \\
\hline & $(0.0174)$ & $(0.0149)$ & $(0.0131)$ & $(0.0135)$ & $(0.0134)$ & $(0.0134)$ & $(0.0123)$ & $(0.0117)$ & $(0.0158)$ \\
\hline \multirow[t]{2}{*}{ ENROLLED } & -0.0237 & -0.00679 & -0.0133 & -0.00131 & -0.00794 & -0.0238 & -0.0367 & $-0.0649^{\star \star \star}$ & $-0.0926^{\star \star \star}$ \\
\hline & $(0.0378)$ & $(0.0324)$ & $(0.0281)$ & $(0.0274)$ & $(0.0265)$ & $(0.0238)$ & $(0.0252)$ & $(0.0241)$ & $(0.0320)$ \\
\hline \multirow[t]{2}{*}{ CONSTANT } & 0.0234 & -1.279 & 1.214 & 2.429 & $3.210^{* *}$ & $3.335^{\star *}$ & $3.324^{* *}$ & $4.250^{\star \star \star *}$ & $6.700^{\star \star \star}$ \\
\hline & $(2.207)$ & $(1.877)$ & $(1.704)$ & $(1.616)$ & $(1.516)$ & $(1.442)$ & $(1.536)$ & $(1.648)$ & $(1.746)$ \\
\hline Time Dummies & Yes & Yes & Yes & Yes & Yes & Yes & Yes & Yes & Yes \\
\hline Observations & 24,443 & 24,443 & 24,443 & 24,443 & 24,443 & 24,443 & 24,443 & 24,443 & 24,443 \\
\hline
\end{tabular}

Bootstrap standard errors in parentheses ${ }^{\star \star *} p<0.01,{ }^{* *} p<0.05,{ }^{*} p<0.1{ }^{*}$ The full set of independent variables from table 2 were included but only the key results are reported in this table to economize on space. 